\title{
Readable Labels and Moderating Effect of Individual Personality Traits Effect on Consumer Healthy Packaged Food Selection Intention
}

\author{
Muhammad Zeeshan Zafar * $\quad$ Noor Azmi Hashim ${ }^{\dagger} \quad$ Fairol Bin Halim ${ }^{\ddagger}$ \\ Shahjahan Masud §
}

\begin{abstract}
It is a common notion that front of pack label guide individual for the selection of healthy and right amount of packaged food. The inconsistent results found in past studies. In continuation with current study proposed a model which is underpinned with theory of planned behavior. The proposed model comprised of factors affecting individual attitude to read food label at point of purchase like traffic lights efficacy, health claim efficacy and user friendly label efficacy, whereas direct impact of subjective norm and self-efficacy was also investigated. Moreover, the personality traits were investigated as moderator. The data collected from three renowned retail outlet of Pakistan named; Al-Fatah, Hyperstar and Metro Cash and Carry. For the in depth study mixed method was used. Therefore, for quantitative date the cross-sectional data was collected with convenience sampling technique using adapted questionnaire whereas for qualitative analysis unstructured questions used for detail interview. The sample size for quantitative analysis was 1146 and for qualitative data 32 interviews were conducted. The results revealed that user friendly label efficacy and health statement efficacy insignificant effect in direct relation whereas full mediation observed with label reading attitude. In contrary to that traffic lights label efficacy has insignificant effect in both direct and indirect relation. Subjective norm and self-efficacy have significant impact on individual intention for healthy food selection. In addition to only two personality traits like; agreeableness and conscientiousness moderated between label reading attitude and intention. The current study implies that consumer education regarding nutrients is necessary.
\end{abstract}

Keywords: Traffic lights efficacy, health statements efficacy, user friendly label efficacy, label reading attitude, personality traits and intention.

\section{Introduction}

The aforementioned studies revealed that growing interest observed among individuals regarding intake of processed and high calorie packaged food (Miocevic \& Zdravkovic, 2020). Therefore, scholars and practitioners suggested to develop sense of healthy packaged food

\footnotetext{
*University Utara Malaysia, Malaysia. Email: zzafarmirza@gmail.com

${ }^{\dagger}$ Faculty School of Business Management, University Utara Malaysia, Malaysia. Email: noorazmie@gmail.com

$\ddagger$ Director (PACE), University Utara Malaysia, Malaysia. Email: fairol@uum.edu.my

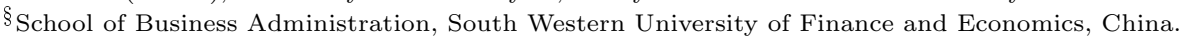

Email: shahjahan.masud@hotmail.com
} 
intention among individuals (Baker et al., 2020). Moreover, statistics reported that consumers are looking to consume healthy food for their health and well-being and they seek low calories and low fat packaged food items at point of purchase. However, consumer found difficult to read food label information due to limited knowledge about nutritional facts table. Hence, it is very difficult to educate consumers to select healthy packaged food because there is no formal method. Therefore, most often consumer preferences to select packaged food are based on their taste, brand name and past experiences (Kaur, Scarborough, \& Rayner, 2017) rather health. Although food label information is mandatory for the guidance and informed choice of consumer at point of purchase, nevertheless empirical results evident that reported behavior and actual behavior of individual about healthy food selection is different (Pomeranz, Wilde, Mozaffarian, \& Micha, 2019).

Practitioners suggested various food label designs like back of pack label $(\mathrm{BoP})$ and front of pack label (FoP). Back of pack labeling is mandatory for describe the main ingredients of product whereas front of pack labeling is an emerging concept which do not need special technical skills to read at point of purchase (Egnell, Talati, Hercberg, Pettigrew, \& Julia, 2018). Consumer preferences differ from segment to segment regarding food label insights (Nystrand \& Olsen, 2020). Therefore, it is very difficult to design a generic food label for every segment. Moreover, consumer interaction with food label also varies from person to person as well as product to product. Health conscious consumers are more concern in reading food label information whereas taste oriented consumer are less conscious about food label information. The content of information at food label regarding nutrients is very decisive. The increase of information at food label can create complexity for consumer at point of purchase (Joo, Lee, Choi, \& Park, 2020). In contrary to that inadequate information can also confuse consumer for getting the insight about food product (Lioutas, 2014). Therefore, the right amount and relevant information can make consumer able for better food choice.

Easily recognizable and understandable information and logos play vital role for healthy food selection (Khandpur et al., 2018). Hence, food processing companies should design food labels easy to understand for consumers. Therefore, FoP label is an emerging concept to facilitate consumers regarding easy to understand information. There are numerous scholars and practitioners who have studied various FoP labels like traffic light labels, health statements and health claims separately to exam their impact on consumer understanding about healthy food items (Vermote, Bonnewyn, Matthys, \& Vandevijvere, 2020). The results are inconsistent. Some of the scholars reported insignificant effect of traffic lights labels. On the other hand some of the scholars have their describe with empirical studies that traffic lights labels with color coded techniques assist consumers at point of purchase for the selection of right amount of packaged food product. In continuation with the impact of health statement also has uncertain impact on consumer healthy packaged food choices. Like some have evident the significant impact of health statements. The advocators of health statement argued that health statements clearly and easily guide consumer with one line statement like 'Low calories, High fiber, High salt'. In contrary to that some of the results revealed that health statements are confusing for consumers for healthy food choices (Egnell et al., 2018). Therefore, author of the current study employed traffic lights efficacy, health statements and friendly food label for double purpose. The first is to 
examine their indirect effect in making food label reading attitude which later effect on healthy food selection intention. The second is to examine their direct effect on intention to select healthy package food. The aforementioned studies have developed a general concept that consumer knowledge about nutrients strongly impact on general usage of food label and food label is not sole influencer for the selection of healthy packaged food.

Consumer internal willingness towards their well-being plays vital role towards food selection (Neulinger et al., 2020). Furthermore, consumer social gathering devise their attitude and intention towards an object and food choices also associated with consumer socially connected people. Therefore, there are some factors which also involved by past researchers to investigate consumer intention towards healthy packaged food like consumer's own internal strength, influence of some influencing people of the society (Egnell et al., 2018) and individual personality factors (World Health Organisation, 2017). In continuation with scholars borrowed self-efficacy from Albert Bandura's social learning theory (1977) to examine consumer internal strength. One the other hand Ajzen theory of planned behavior (1991) helps scholars with subjective norm to examine the influencing factors of individuals towards their intention (Anastasiou, Miller, \& Dickinson, 2019). Therefore, researcher of the current study involved subjective norm and self efficacy to test their direct impact on consumer intention towards selection of healthy packaged food intention.

Similarly, the significance of food label is inevitable for consumer education towards nutrients. Researchers and practitioners are still in quest of customized food label schemes. The food consumption behaviors is an complex subject and studies accounted that there are numerous factors involved which shape individual preference towards food selection and personality traits is also one of them. Personality traits play pivotal role in shaping consumers' willingness to consult food label at point of purchase (Chaturvedi, Kulshreshtha, $\&$ Tripathi, 2020). There are five personality traits, conscientiousness, openness to experience, agreeableness, extraversion and neuroticism. The aforementioned studies have accounted that individual's personality traits are also linked with the consumption pattern of food (Pomeranz et al., 2019). Moreover, the five personality traits also having inconsistent results while impacting on consumer packaged food consumption intention. Like lower conscientiousness and higher neuroticism, as well as lower openness to experience and higher extraversion, are found to be associated with obesity (Sacks, Rayner, \& Swinburn, 2009; Pfeiler \& Egloff, 2020). Similarly, Keller and Siegrist (2015) reported the complex relationship between personality traits and food preferences and empirically tested that the conscientiousness trait is associated with fruit and vegetable and neuroticism is linked with unhealthy food selection.

To bridge the gap in literature regarding personality impact on healthy packaged food selection researcher of the current study employed five personality traits as moderator. The intention of the current study is to investigate the combine impact of personality traits and attitude towards consumer intention for healthy packaged food selection. 


\section{Literature Review}

Food label information encourages consumers for informed food selection. Studies witnessed that food label guide consumers regarding nutrients and label information make consumer able for right product selection (Kaur et al., 2017). In contrary to that aforementioned studies reported inconsistent results about the usefulness of food label information. Some scholars revealed that food label information need technical skills to understand the nutrients displayed at food label (Ayaz, Dedebayraktar, Inan-Eroglu, Besler, \& Buyuktuncer, 2020). On the other hand some have the opinions that food label format has detailed information for the assistance of consumer at point of purchase (Werle, Trendel, \& Ardito, 2013). The back of pack labels are the mandatory labels and every food processing company must have to follow the international format while writing nutritional information. The nutritional fact table in back of label is a technical and statistical format regarding nutritional information. It needs special proficiency to understand. In contrary to that front of pack label is a voluntary label format. Therefore, scholars and practitioners suggested to use these formats for the convenience and to educate consumer for healthy packaged food selection. The researchers of the current study employed front of pack label formats to understand their impact on reading attitude and later in making consumer intention for healthy packaged food selection. Moreover, for the investigation of intention Ajzen proposed a theory named theory of planned behavior, therefore the current study model is underpinned with theory of planned behavior. Similarly, the food selection is most often linked with individual likes and dislikes therefore to examine individual personality impact on intention the researchers of the current study employed big five personality traits. The variables used in the current study are; traffic lights label efficacy, health statement efficacy, user friendly label efficacy as a predictor of intention with the mediation of food label reading attitude. Similarly, the impact of subjective norm and self-efficacy on intention was also examined with direct relation. In addition to the five personality traits used as moderator between food label reading attitude and intention.

\section{Health Statement Efficacy and Food Label Reading Attitude}

The simple and easy to read statement like 'low calories', 'low fat' and 'high fiber' most often having long lasting impact on consumer mind at point of purchase (Van Herpen \& Van Trijp, 2011). These statements provide the nutritional guidance and also demonstrate the prominent nutrient in food items which later help consumer for packaged food selection. The aforementioned studies witnessed that health statements educate consumers and inform individual about the nutrients link with consumer health (Díaz, Fernández-Ruiz, \& Cámara, 2020). The health statement format of front of pack label grab consumer attention at point of purchase and these statements play vital role to transform consumer attitude from casual purchase behavior towards package food selection to consciously reading of food label before selection (Tan, van der Beek, Kuznesof, \& Seal, 2016). On the other hand there are some studies which reported insignificant effect of health statement on food label reading attitude (Neuhofer et al., 2020). Some of the past studies argued that health statements are the brief statements about one nutrient whereas consumer need complete 
guidance about the composition of packaged food items (Clarke et al., 2020). Therefore, researchers of the current study have developed following hypothesis;

H1: Health Statement Efficacy significantly effect on food label reading attitude and food label reading attitude mediates between health statement efficacy and intention for healthy packaged food.

\section{Traffic Lights Label Efficacy and Food Label Reading Attitude}

The color coded scheme of front of pack food label introduced by British Food Agency (2009) with named traffic lights rating system for nutrients guidance of consumer (Hagmann \& Siegrist, 2020). The aforementioned studies accounted that display of nutrients information with the association of traffic lights symbols like red, yellow green create awareness among consumer to select healthy packaged food (Jackey, Cotugna, \& Orsega-Smith, 2017). The consumer familiarity with traffic lights in their daily routine life helps consumer in selection of packaged food. Because food processing companies use same color behavior of traffic lights color for nutrients as these colors behavior in traffic rules. Furthermore, it is observed in empirical studies that consumer most often in rush while shopping in grocery retail outlets and did not bother to read even one statement regarding nutrients. Therefore, these traffic lights color scheme with nutritional relation helps consumer to take instant decision for packaged food selection intention (Sacks et al., 2009; Sharf et al., 2012). The traffic lights label format of front of pack label is appealing and attractive for consumer nevertheless studies reported some contradictory results in literature regarding the usefulness of color scheme. The aforementioned studies accounted that usefulness of traffic lights label to educate consumer about nutrients varies from person to person (Lioutas, 2014). In continuation with sometime consumer demand detailed information to read about nutrients while choosing packaged food product (Goldberg, 1992). On the other hand sometime crowded food label makes consumer reluctant to consult food label information. These inconsistent results in past literature motivated consumer to examine the impact of traffic lights label efficacy. Therefore, the hypothesis of the study is;

H2: Traffic lights label (TLL) efficacy significantly effect on food label reading attitude and food label reading attitude mediates between TLL efficacy and intention for healthy packaged food.

\section{Food Label Reading Efficacy and Healthy Packaged Food Intention}

The decreasing trend of physical activity as well as eating unhealthy food is becoming the cause chronic diseases among people (World Health Organisation, 2017a). Food processing companies are putting their efforts and taking measure to guide and help consumer to select healthy packaged food items for their daily life (Kaur et al., 2017; Ketelsen, Janssen, \& Hamm, 2020). The food processing companies are using the food label as a source of guidance for consumers by describing maximum and relevant information regarding food product. The two sides of food label like; the first the mandatory back of pack (BoP) 
food label and second the voluntary front of pack (FoP) food label are the representative of food label information for consumer assistance at the point of purchase (Van Herpen \& Van Trijp, 2011). The BoP is comprised of the technical and detailed information about food nutrients (). On the other hand FoP consists of the usefulness of nutrients with brief statements and color coded logs for conveniently understanding of individuals (Banovic, Reinders, Claret, Guerrero, \& Krystallis, 2019). Although companies using both part of food label simultaneously nevertheless the results regarding efficacy of both labels are inconsistence. The food processing companies following their concern GOVT policies for describing the nutritional information at both food label formats but the policy can only effective when consumer consult food label at point of purchase (Nam, 2020). In addition to the aforementioned studies reported that consumer's opinions about food label efficacy differ from country to country as well as product to product. The scholars conducted their studies for the investigation of food label efficacy by involving various formats of food label. The aforementioned studies revealed that U. S population demand nutritional fact panel for the selection of healthy packaged food (Capacci et al., 2012). In contrary to that European population required the association of traffic lights label with food nutrients and find logo oriented food label more useful. These uncertain empirical evidences unfold the fact that still scholars and practitioners are seeking generalized food label format for the convenience of consumer (Nieto et al., 2020). Therefore, the researchers of the current study hypothesized that the overall food label efficacy can make consumer attitude to read food label at point of purchase which later develop consumer intention for healthy packaged food. The hypothesis will be;

H3: Food Label Efficacy significantly effect on food label reading attitude and food label reading attitude mediates between food label efficacy and intention for healthy packaged food.

\section{Theory of Planned Behavior and Food Selection Intention}

The most widely used theory for the investigation of consumer behavior is theory of planned behavior. Furthermore, the behavioral model was developed by Icek Ajzen in 1985 for the wide verity of investigation of behavioral intention and the behavioral intention explained by three factors like attitude, subjective norm and perceived behavioral control (Asif, Xuhui, Nasiri, \& Ayyub, 2018). In addition to some of the researchers used Albert Bandura's self-efficacy in replace of perceived behavioral control to examine the behavioral intention. The current model is underpinned with theory of planned behavior.

\section{Food Label Reading Attitude and Healthy Packaged Food Intention}

Attitude is the first and highly influential determinant of intention. According to Icek Ajzen attitude is "the degree to which a person has a favorable or unfavorable evaluation or appraisal of the behavior in question". Moreover, attitude is the mental state of an individual that reflects their positive or negative evaluation towards any behavior. The aforementioned studies have advocated that a strong attitude can be raised through specific 
and salient behavioral beliefs which later make strong intention of individual towards any object (Pourmoradian, Kermanshahi, Chaeipeima, Farazkhah, \& Roudsari, 2020). Similarly, the behavioral beliefs determine the consequence of particular behavior. Past studies results revealed that making strong attitude of an individual for consulting food label at point of purchase play significant role in selection of healthy packaged food products (Rizkitysha \& Hananto, 2020). Hence forth, the strength of attitude is directly proportion to the strong intention and strong actual behavior. The empirical results accounted for the decisiveness of food label reading attitude and indicate that individual attitude to read food label information make consumer able to avoid less-caloric and unhealthy food and prefer healthy packaged food products. In addition to food label reading attitude elicit the consumer intention towards healthy and balanced packaged food intention. Therefore, the authors of the current study hypothesized that;

\section{H4: Food label reading attitude significantly effect on intention for healthy packaged food.}

\section{Subjective Norm and Healthy Packaged Food Intention}

The current study postulates that subjective norm having positive significant impact on developing individual intention towards healthy packaged food selection. According to the basic definition of subjective norm "the perceived social pressure to perform or not to perform the behavior" (Ajzen, 1991). As per the definition of subjective norm Ajzen determined that individual decisions towards any object can be influenced by some people of the society who are having recognizable opinions (Dunn et al., 2011). Similarly, these opinion leaders are considered to be very close and important for others (Conner, 2020). Like behavioral beliefs for attitude, the normative beliefs are the predictor of subjective norms (Jun \& Arendt, 2016). These normative beliefs motivate and de-motivate individuals in developing their intention towards any objective. Although person's decisions are based on their own past experiences nevertheless there are some acquaintances and family members whose past experiences also effect on individual intention (Dalila, Latif, Jaafar, Aziz, \& Afthanorhan, 2020). There are numerous studies which reported that subjective strongly effect on individual intention for healthy packaged food selection. Although several scholars have investigated the impact of subjective norm nevertheless the results are inconsistence. Some of the research finding unfolded that subjective norm has strong impact on intention, in contrary to that some have reported the weak effect (Nguyen et al., 2020) and some have insignificant influence (Rohman, Abadi, Soelton, Prasetyo, \& Saratian, 2020) To bridge this inconsistency in past literature the researchers of the current study hypothesized that;

H5: Subjective Norm significantly effect on intention for healthy packaged food. 


\section{Self-Efficacy and Healthy Packaged Food Intention}

The third determinant of intention is perceived behavioral control. According of Icek Ajzen the definition of perceived behavioral control is "the perceived ease or difficulty of performing the behavior" (Liou \& Kulik, 2020). The definition revealed that although external factors influencing individual's attitude and making their intention towards any behavior but individual inner strength and willingness is also very significant (Maleksaeidi, Ranjbar, Eskandari, Jalali, \& Keshavarz, 2018). The past scholars have used self-efficacy which is the construct of Albert Bandura's social learning theory in replace of perceived behavioral control (Chang, Ma, \& Chen, 2020). Moreover, the theory of planned behavior was not designed to investigate the behavioral change of individual (Cai \& Leung, 2020). According to Bandura the self-efficacy is "the individual's belief they can successfully undertake a particular behavior in order to achieve an outcome". The aforementioned studies reported that in health and dietary intention self-efficacy explain better as compare to perceived behavioral control (Bandura, 1982). Therefore, there is need to employ the construct which can achieve the objective of the current study and self-efficacy is a preferred variable. Therefore, the current study hypothesized that;

H6: Self-Efficacy significantly effect on intention for healthy packaged food.

\section{Personality Traits and Food Selection Behavior}

Goldberg (1992) introduced personality factors of an individual with the name "Big Five Personality Factors". The factors comprised of five personality traits like conscientiousness, agreeableness, openness to experience, extraversion and neuroticism. These traits used in investigation of various purposes and their decisiveness also examined in finding individual food preferences. Some of the studies unfolded the fact that the impact of personality traits is twofold like in increasing or decreasing on any outcome (Yasunaga \& Yaguchi, 2014). Moreover, studies have accounted that personality traits design individual dietary pattern. The personality traits play vital role in food related decision making (Sivrikaya \& Pekerssen, 2020). Similarly, the effect of each trait is different like extraversion trait is linked with obesity and overweight, on the other hand neuroticism is associated with underweight (Kakizaki et al., 2008), the conscientiousness is effecting on healthy dietary intake (Coderoni \& Perito, 2020). The aforementioned studies revealed that personality traits and dietary habits are an established relationship (Bukhari et al., 2020). Therefore, the researchers of the current study hypothesized that;

H7: Five personality traits moderates between food label reading attitude and intention for healthy packaged food.

\section{Theoretical Framework}

The proposed model in figure 1 is underpinned with Ajzen's theory of planned behavior (TPB). The aforementioned studies employed TPB to investigate the relationship between numerous variables and intention towards an object (Conner, 2020). The construct of TPB 
comprised of beliefs, attitude, subjective norm, perceived behavioral control/self-efficacy, intention and actual behavior. The Ajzen proposed that selection of relevant beliefs explain better attitude which forward its strong impact on intention and strong intention develop strong actual behavior (Ajzen, 2020). Therefore, the current study has involved front of pack (FoP) label formats like traffic lights efficacy, health statements and user friendly label as a beliefs for making individual attitude to read food label. In addition to the individual decisions towards healthy packaged food choices most often influenced by some influencing people of society therefore subjective norm used to explain its effect on individual intention for the selection of healthy packaged food items. Moreover, perceived behavior control differentiates TPB from theory of reasoned action (TRA). There are some studies in the past which used Albert Bandura self-efficacy instead of perceived behavior control. Therefore, current study used self-efficacy to investigate its impact on intention. Similarly, researcher of the current study interested to examine the effect of personality. Therefore, personality traits used as moderator between attitude and intention. The purposed to investigate the moderating effect of personality traits between attitude and intention is to identify that when strong beliefs make individual's strong attitude which later develop strong intention how individual personality can make difference.

Figure 1

Healthy packaged food intention with theory of planned behavior

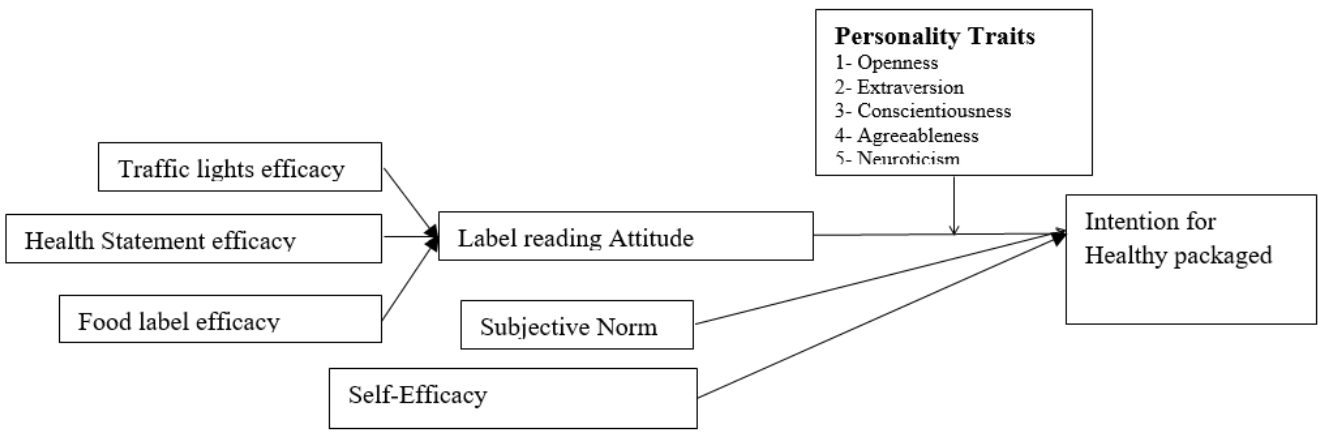

\section{Methods}

Cross sectional data collected with convenience sampling technique. For data collection researcher used adapted questionnaire having total of 87 questions for 12 variables. Packaged food items are the commonly used products and individual opinions at the point of purchase can better represent their intention. Therefore, researcher collected participant's response in retail outlets. Moreover, past studies supported that a study conducted in Paris to investigate consumer intention towards packaged food choices used same method for data collection (Julia et al., 2015) and researchers collected data from Paris three well known retail outlets. Similarly, packaged food items are available at all small and big retail shelves but researcher selected three renowned retail outlets like Hyperstar, Matro cash and carry and Al-Fatah. It is very difficult to involve customer randomly while he/she is 
engage in shopping various products. Therefore, researcher contacted retail management for data collection and get formal permission. The retail management suggested that they offer membership cards to their customers and they are their loyal customer. Therefore, it is better to contact these customers for data collection. The objective of the study discussed in detail with retail management. The retail management received the questionnaire and asked that they will contact to their customer for data collection. The retail management of three retail outlets contacted their member customer and 1543 have shown their willingness to participate in survey. Therefore, after three weeks intense effort and with multiple reminders 1241 participants returned filled questionnaire. In addition to researcher was interested to used mixed method for in depth study. Although quantitative research technique provides breadth in research but offers limited depth whereas qualitative method adds depth and deeper understanding of individuals' emotions and attitudes. Therefore, the mix method was adopted for data collection. Therefore, for this purpose qualitative data was collected through unstructured questionnaire. The participants for in depth interview were those who were involve in quantitative data survey, but for qualitative data only 23 participants have showing their intention. Furthermore, to determine the factors which explain consumer intention to select healthy packaged food researcher used structural equation modeling and for data analysis researcher employed AMOS for model fitness and to examine the causal relationship between exogenous and latent endogenous variables. For the analysis of data structural equation modeling was used. The causal relations between latent exogenous and latent endogenous variables were measured with a standard coefficient and significance value of AMOS. The adequate fit was observed in the present study by comparing with standard fit indices. The detail of adapted questionnaire is given in table 1. For in depth interviews researchers used unstructured questions. The questions were extracted from the adapted questionnaire. Additionally, the unstructured questions were simple statements. The detail is given in table 2. Both table 1 and table 2 are reported in Appendix 1.

\section{Analysis}

The distributed questionnaires were 1543 and researchers received 1043 filled questionnaires. The response rate was $68 \%$. In filled questionnaires researchers found that there 298 participants filled only $50 \%$ of the questionnaire. Therefore, these questions were excluded. Moreover, there were 127 questionnaires having missing values less than $20 \%$ of the total 87 questions. To solve missing data issue researchers conducted imputation method. Similarly, to test the outlier of the questionnaire researchers conducted Mahalanibies test (Hair, Anderson, Babin, \& Black, 2010). After conducted Mahalanobies test few of the questionnaires were deleted and remaining questionnaires were 713 for final analysis. The demographical factors were not the part of main model analysis therefore researchers collected gender, profession and age related data. In 713 questionnaires there were 312 female and 401 were male participants. In addition to the average age of female were 33 and male were 35 . Furthermore, $43 \%$ female were working women and rest was house wives. On the other hand $37 \%$ male were self-employed and rest were salaried person. 
Table 3

CR, AVE and Factor Loading

\begin{tabular}{|c|c|c|c|}
\hline Variables & Factor Loading & AVE & CR \\
\hline \multicolumn{4}{|c|}{ Traffic Lights label efficacy } \\
\hline TLS2 & 0.785 & 0.561 & 0.774 \\
\hline TLS3 & 0.873 & & \\
\hline TLS4 & 0.716 & & \\
\hline TLS5 & 0.721 & & \\
\hline TLS1 & 0.775 & & \\
\hline \multicolumn{4}{|c|}{ Health statement } \\
\hline $\mathrm{HC} 2$ & 0.749 & 0.541 & 0.754 \\
\hline $\mathrm{HC} 3$ & 0.762 & & \\
\hline $\mathrm{HC} 4$ & 0.753 & & \\
\hline \multicolumn{4}{|c|}{ User Friendly Food Label efficacy } \\
\hline UFL1 & 0.63 & 0.552 & 0.732 \\
\hline UFL3 & 0.757 & & \\
\hline UFL4 & 0.778 & & \\
\hline UFL5 & 0.764 & & \\
\hline \multicolumn{4}{|c|}{ Subjective Norms } \\
\hline SN1 & 0.826 & 0.674 & 0.724 \\
\hline SN2 & 0.734 & & \\
\hline SN3 & 0.715 & & \\
\hline SN6 & 0.602 & & \\
\hline SN7 & 0.743 & & \\
\hline \multicolumn{4}{|l|}{ Self-Efficacy } \\
\hline SE1 & 0.896 & 0.573 & 0.798 \\
\hline SE2 & 0.723 & & \\
\hline SE7 & 0.752 & & \\
\hline SE8 & 0.844 & & \\
\hline SE9 & 0.776 & & \\
\hline \multicolumn{4}{|c|}{ Food label reading Attitude } \\
\hline ATFL2 & 0.877 & 0.671 & 0.748 \\
\hline ATFL3 & 0.724 & & \\
\hline ATFL4 & 0.76 & & \\
\hline ATFL5 & 0.633 & & \\
\hline \multicolumn{4}{|c|}{ Conscientiousness } \\
\hline PTraitA2 & 0.776 & 0.532 & 0.72 \\
\hline PTraitA3 & 0.794 & & \\
\hline PTraitA4 & 0.636 & & \\
\hline PTraitA5 & 0.676 & & \\
\hline \multicolumn{4}{|c|}{ Openness to Experience } \\
\hline PTraitB4 & 0.63 & 0.586 & 0.728 \\
\hline PTraitB5 & 0.783 & & \\
\hline PTraitB6 & 0.771 & & \\
\hline \multicolumn{4}{|c|}{ Agreeableness } \\
\hline PTraitC2 & 0.775 & 0.663 & 0.741 \\
\hline PTraitC3 & 0.771 & & \\
\hline PTraitC4 & 0.751 & & \\
\hline PTraitC5 & 0.717 & & \\
\hline PTraitC6 & 0.693 & & \\
\hline \multicolumn{4}{|c|}{ Openness to Experience } \\
\hline PTraitD1 & 0.795 & 0.596 & 0.734 \\
\hline PTraitD2 & 0.832 & & \\
\hline PTraitD3 & 0.776 & & \\
\hline PTraitD7 & 0.747 & & \\
\hline \multicolumn{4}{|c|}{ Neuroticism } \\
\hline PTraitE3 & 0.671 & 0.630 & 0.758 \\
\hline PTraitE4 & 0.73 & & \\
\hline PTraitE5 & 0.71 & & \\
\hline PTraitE6 & 0.61 & & \\
\hline PTraitE7 & 0.688 & & \\
\hline \multicolumn{4}{|c|}{ Intention for Healthy Package Food } \\
\hline HPFCI4 & 0.716 & 0.575 & 0.797 \\
\hline HPFCI5 & 0.866 & & \\
\hline HPFCI6 & 0.81 & & \\
\hline HPFCI7 & 0.798 & & \\
\hline
\end{tabular}


The values of factor loading, reported in table 3. Fornell and Larcker (1981) suggested to conduct convergent and discriminant validity test to examine the validity of constructs. The cutoff value of composite reliability is 0.60 whereas some of the researchers reported that 0.70 better explain the composite reliability (Nunnally, 1994). Similarly discriminant validity tested with average variance extraction (AVE). The criteria for AVE are that the square value of correlation of two variables must be less than the AVE. Furthermore, if the square root of the average variance extracted (AVE) is greater than the square of the standardized correlation value of two constructs indicates the discriminant validity. The AVE value should be more than 0.50 (Fornell \& Larcker, 1981). The analysis of current study revealed that collected data did not violated the discriminant validity of AVE, composite reliability (CR) rules of thumb. Researchers of the study also conducted confirmatory factor analysis. AVE and CR reported in table 4.

Table 4

Discriminant Validity

\begin{tabular}{|c|c|c|c|c|c|c|c|c|c|c|c|c|}
\hline Variables & 1 & 2 & 3 & 4 & 5 & 6 & 7 & 8 & 9 & 10 & 11 & 12 \\
\hline Openness & 0.756 & & & & & & & & & & & \\
\hline TLL Efficacy & 0.174 & 0.732 & & & & & & & & & & \\
\hline HS Efficacy & 0.135 & 0.543 & 0.724 & & & & & & & & & \\
\hline SN & 0.253 & 0.33 & 0.357 & 0.776 & & & & & & & & \\
\hline SE & 0.152 & 0.329 & 0.339 & 0.368 & 0.751 & & & & & & & \\
\hline IHPF & 0.286 & 0.352 & 0.437 & 0.592 & 0.457 & 0.734 & & & & & & \\
\hline Extraversion & 0.644 & 0.171 & 0.189 & 0.22 & 0.206 & 0.386 & 0.744 & & & & & \\
\hline Agreeableness & 0.544 & 0.147 & 0.149 & 0.19 & 0.182 & 0.368 & 0.573 & 0.749 & & & & \\
\hline Conscientiousness & 0.689 & 0.17 & 0.134 & 0.231 & 0.166 & 0.299 & 0.673 & 0.562 & 0.76 & & & \\
\hline Neuroticism & 0.588 & 0.141 & 0.28 & 0.189 & 0.148 & 0.273 & 0.535 & 0.548 & 0.639 & 0.765 & & \\
\hline UFFL Efficacy & 0.261 & 0.454 & 0.533 & 0.43 & 0.344 & 0.476 & 0.291 & 0.284 & 0.272 & 0.296 & 0.75 & \\
\hline FLR Attitude & 0.182 & 0.37 & 0.556 & 0.564 & 0.408 & 0.533 & 0.246 & 0.304 & 0.196 & 0.242 & 0.413 & 0.758 \\
\hline
\end{tabular}

The researchers of the current study used structural equation model (SEM) for model analysis as well as to test the measurement and model tested on AMOS. In addition to, figure 2 is the graphical output of the measurement test. The output revealed that theoretically factors are close to each other (Hair et al., 2010). Furthermore more to gain the goodness of fit some of the items deleted. The results are reported in table 5 .

Table 5

Confirmatory Factor analysis of all measurement and Goodness of fit

\begin{tabular}{lcccccccccc}
\hline Code & Items & R- Items & Chi-S & CMIN & CFI & GFI & AGFI & NFI & RMSEA & P-V \\
\hline TLL Efficacy & 6 & 5 & 3.422 & 1.761 & 0.997 & 0.997 & 0.98 & 0.99 & 0.038 & 0.172 \\
HS Efficacy & 7 & 5 & 7.304 & 1.681 & 0.996 & 0.994 & 0.981 & 0.99 & 0.038 & 0.135 \\
UFL Efficacy & 8 & 5 & 11.769 & 2.554 & 0.997 & 0.997 & 0.984 & 0.993 & 0.038 & 0.172 \\
FLR ATI & 8 & 4 & 1.216 & 1.108 & 0.998 & 0.999 & 0.99 & 0.995 & 0.014 & 0.330 \\
SN & 7 & 4 & 3.019 & 2.010 & 0.998 & 0.996 & 0.981 & 0.996 & 0.043 & 0.134 \\
SE & 9 & 5 & 7.478 & 1.696 & 0.994 & 0.99 & 0.982 & 0.976 & 0.036 & 0.132 \\
Extra & 7 & 5 & 2.687 & 0.737 & 0.999 & 1.00 & 0.992 & 0.992 & 0.000 & 0.595 \\
Agree & 7 & 4 & 3.101 & 2.000 & 0.996 & 0.996 & 0.982 & 0.993 & 0.043 & 0.135 \\
Cons & 7 & 4 & 2.562 & 1.231 & 0.998 & 0.999 & 0.988 & 0.997 & 0.021 & 0.292 \\
Nuro & 7 & 4 & 3.653 & 1.727 & 0.997 & 0.998 & 0.984 & 0.994 & 0.037 & 0.178 \\
Opne & 7 & 4 & 3.75 & 2.075 & 0.996 & 0.996 & 0.981 & 0.992 & 0.045 & 0.126 \\
ENDO & 7 & 4 & 2.917 & 1.408 & 0.997 & 0.999 & 0.987 & 0.995 & 0.028 & 0.245 \\
EXO & 80 & 29 & 325 & 1.068 & 0.99 & 0.96 & 0.945 & 0.94 & 0.011 & 0.202 \\
EXO/END & 87 & 30 & 365.98 & 1.080 & 0.995 & 0.957 & 0.941 & 0.936 & 0.012 & 0.150 \\
\hline
\end{tabular}


Figure 2

Exogenous and endogenous confirmatory factor analysis

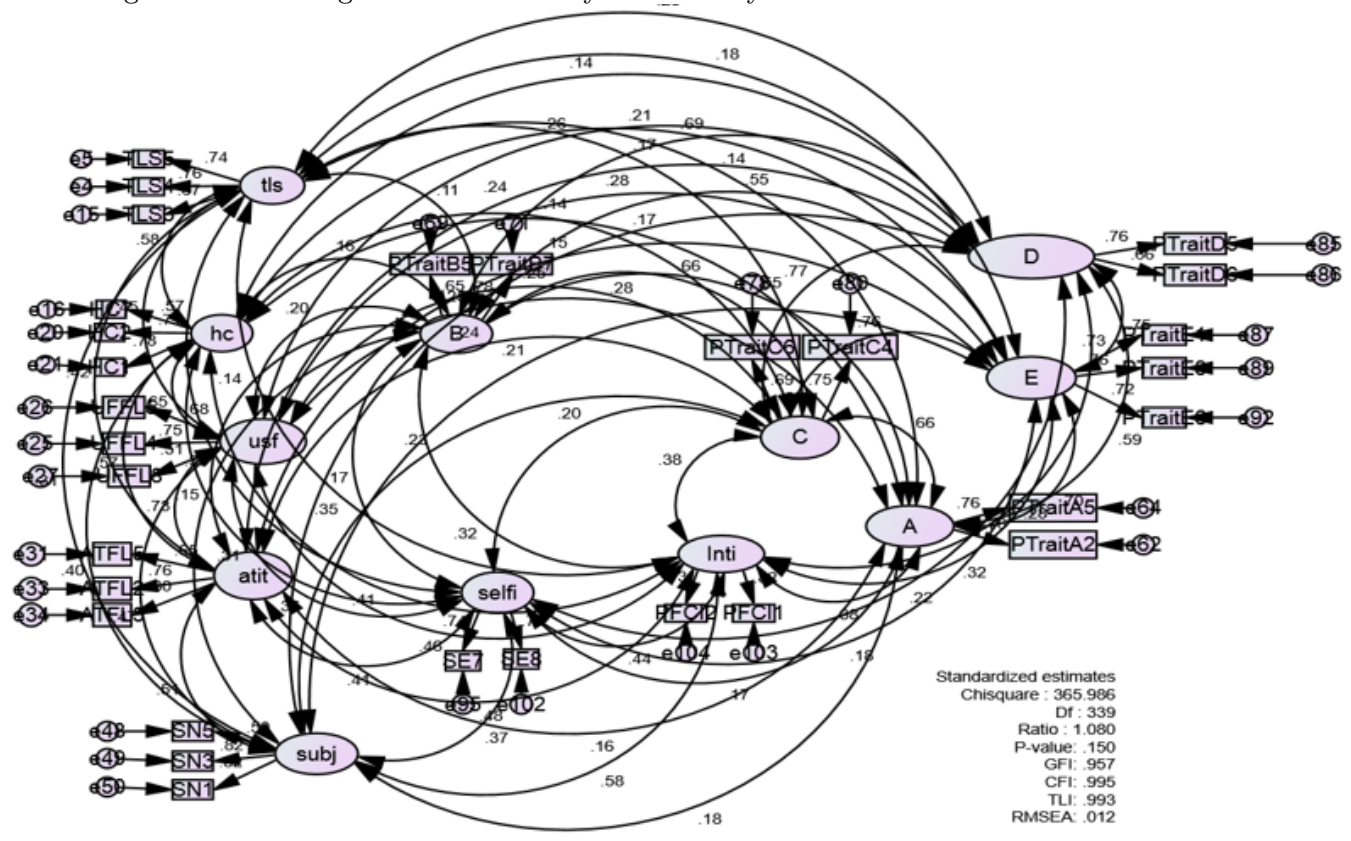

The researchers of the current study developed hypotheses with direct and indirect relationships. Moreover, initially the model was examined with absolute, incremental and parsimonious. The model fitness examined with the ration of NFI, IFI,TLI,CFI, RMSEA, AGFI and GFI. The results of model fitness reported in table 6. Similarly, the output of the model fitness graphically reported with figure 3 .

Table 6

Hypothesized model goodness of fit

\begin{tabular}{|c|c|c|}
\hline Indicators & $\begin{array}{c}\text { Hypothesized } \\
\text { Model }\end{array}$ & $\begin{array}{l}\text { Threshold Values } \\
\text { (Hair et al., 2010) }\end{array}$ \\
\hline \multicolumn{3}{|l|}{ Absolute } \\
\hline Chi-Square & 152.676 & \\
\hline DF & 138 & Less than 2 \\
\hline Ratio/CMIN & 1.186 & \\
\hline \multicolumn{3}{|l|}{ Incremental } \\
\hline CFI & 0.932 & Greater Than 0.90 \\
\hline GFI & 0.959 & Greater Than 0.90 \\
\hline AGFI & 0.936 & Greater Than 0.90 \\
\hline NFI & 0.922 & Greater Than 0.90 \\
\hline \multicolumn{3}{|c|}{ Parsimonious } \\
\hline RMSEA & 0.018 & $\begin{array}{l}\text { Less than } 0.080 \\
\text { (Lesser is better) }\end{array}$ \\
\hline $\mathrm{P}$-value & 0.058 & $\begin{array}{l}\text { Greater Than } 0.05 \\
\text { (Bigger is better) }\end{array}$ \\
\hline
\end{tabular}

The proposed model achieved goodness of fit indices and in second stage researchers 
conducted the path model test to examine the effect of independent variable on dependent variable. The results revealed that user friendly label efficacy, health statement efficacy significant effect with attitude and insignificant effect with intention. On the other hand subjective norm and self-efficacy have significant effect on intention. The table 7 comprised of direct relationship results of proposed model.

Figure 3

Hypothesized model after fit
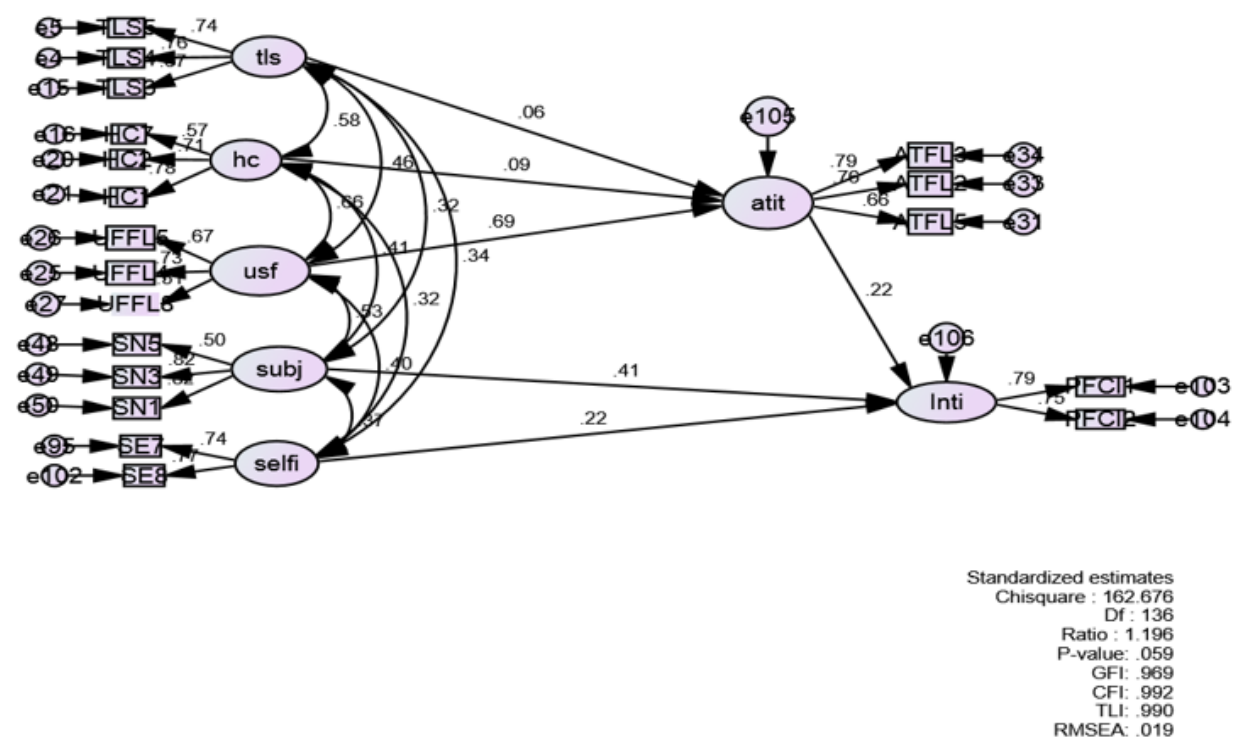

Table 7

Hypotheses standardized results

\begin{tabular}{llcccccc}
\hline End0 & & Exoge & Estimate & S.E. & C.R. & P & Status \\
\hline FLR Attitude & $<-$ & UFL Efficacy & 0.572 & 0.094 & 4.302 & 0.023 & Signi \\
FLR Attitude & $<-$ & HS Efficacy & 0.377 & 0.123 & 2.385 & 0.037 & Signi \\
FLR Attitude & $<-$ & TLL Efficacy & 0.031 & 0.065 & 0.576 & 0.465 & Insigni \\
Intention & $<-$ & SN & 0.592 & 0.17 & 5.39 & $* * *$ & Signi \\
Intention & $<-$ & SE & 0.186 & 0.077 & 2.413 & 0.036 & Signi \\
Intention & $<-$ & Attitude FLR & 0.151 & 0.115 & 2.701 & 0.017 & Signi \\
Intention & $<-$ & TLL Efficacy & -0.077 & 0.106 & -0.253 & 0.601 & Insigni \\
Intention & $<-$ & HS Efficacy & 0.191 & 0.197 & 0.613 & 0.44 & Insigni \\
Intention & $<-$ & UFL Efficacy & -0.131 & 0.183 & -0.554 & 0.38 & Insigni \\
\hline
\end{tabular}

The researchers of the current study developed model with mediation relationship and traffic lights label efficacy (TLL), health statement efficacy (HS) and user friendly label efficacy (UFL) effecting intention for healthy packaged food with the mediation of food label reading attitude. After analysis the results unfolded that UFL and HS have full mediation whereas TLL has no mediation. The statistics are reported in table 8 . 
Table 6

Mediation effect of Attitude towards food label

\begin{tabular}{cccccccc}
\hline Endo & Mediator & Exoge & Estimate & S.E. & C.R. & P & Status \\
\hline Intention & Attitude & UFL Efficacy & 0.402 & 0.084 & 4.202 & 0.023 & Full Mediation \\
Intention & Attitude & HS Efficacy & 0.377 & 0.143 & 2.485 & 0.037 & Full Mediation \\
Intention & Attitude & TLL Efficacy & 0.091 & 0.075 & 0.476 & 0.465 & No Mediation \\
\hline
\end{tabular}

The researchers of the current study employed personality traits as moderator between attitude and intention. The objective was to investigate the combine effect of five personality traits and attitude on intention. The moderation model was run on AMOS and output of the model graphically represented in figure 4 .

Figure 4

Moderation effect of Personality Traits

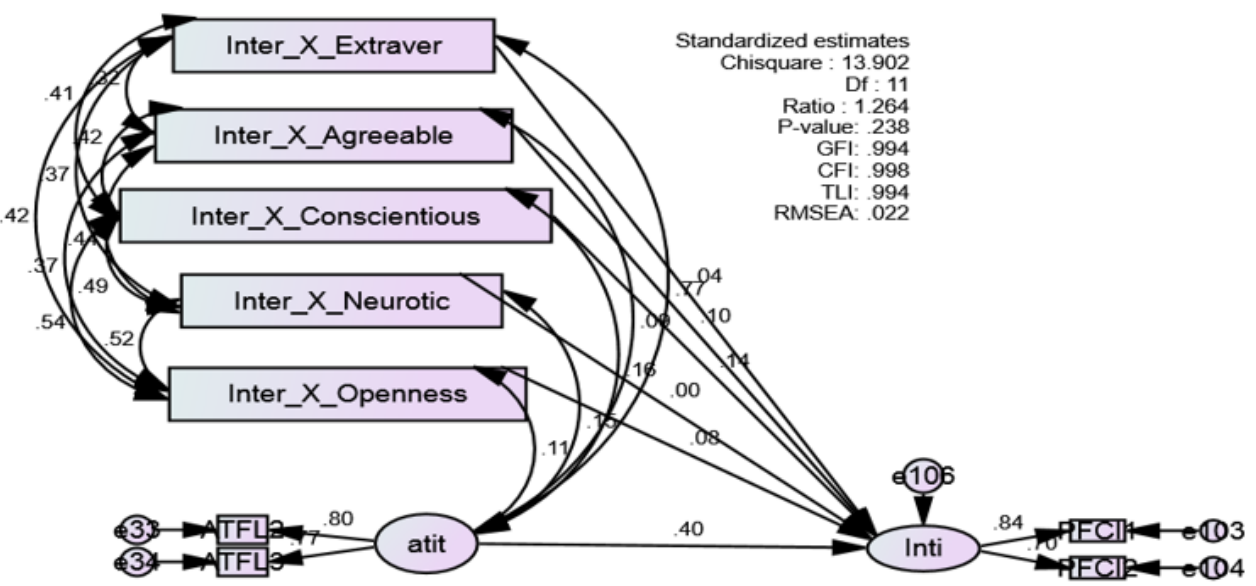

Table 9

Moderation effect of five personality traits

\begin{tabular}{lccccccc}
\hline Endo & Moderator & Predictor & Estimate & S.E. & C.R. & P & Status \\
\hline Inti & $<-$ & Attitude & 0.357 & 0.162 & 3.486 & 0.05 & Signi \\
Inti & Extraversion & Attitude & 0.075 & 0.049 & 0.379 & 0.631 & No Moderation \\
Inti & Agreeableness & Attitude & 0.124 & 0.034 & 1.912 & 0.028 & Moderation \\
Inti & Conscientiousness & Attitude & 0.157 & 0.025 & 2.476 & 0.006 & Moderation \\
Inti & Neuroticism & Attitude & 0.023 & 0.025 & 0.062 & 0.919 & No Moderation \\
Inti & Openness & Attitude & 0.064 & 0.037 & 1.329 & 0.188 & No Moderation \\
\hline
\end{tabular}

The statistical results of moderation hypothesis reported in table 9. Researchers examined the five personality traits moderated effect individually. The output accounted that agreeableness and conscientiousness significantly moderated. On the other hand, there is no effect of extraversion, openness to experience and neuroticism on intention.

Mixed method used in current study to examine the detail effect of respondents for the selection of healthy packaged food. Therefore, researchers provided unstructured question- 
naires for qualitative data. The unstructured questions facilitate participants to response with compete freedom rather in confined system like Likert scale. The researchers collected qualitative data of 23 participants and unstructured answers were analyzed using Nvivo11. Nvivo develop theme with frequently used words as well as extract the most commonly utter sentences. The output of word cloud and word sentences presented in figure 5 and 6 .

Figure 5

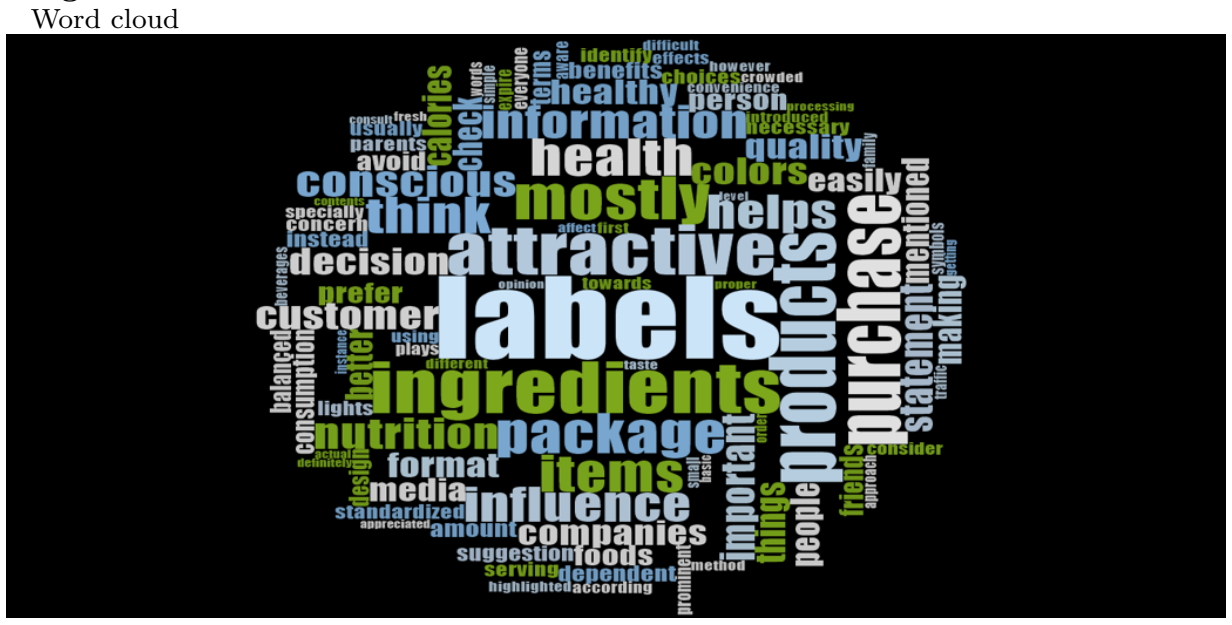

Figure 6

Word cloud

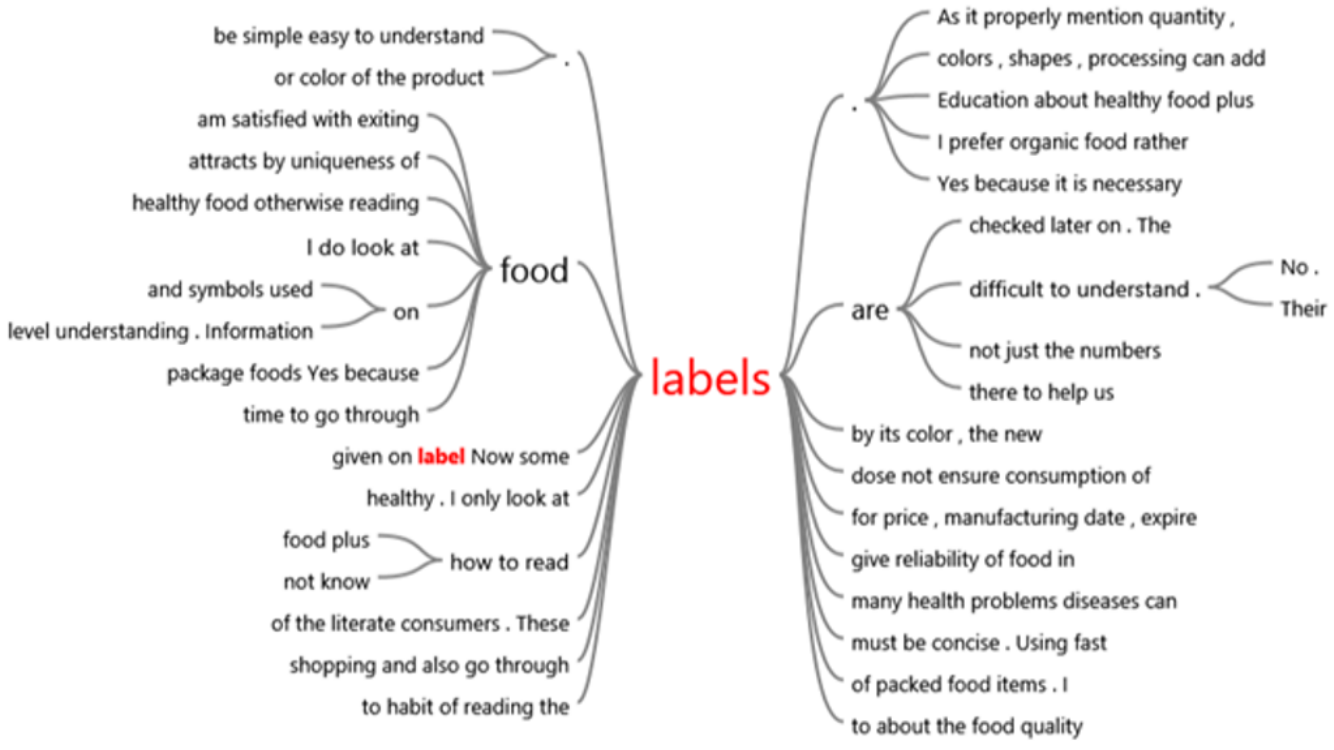




\section{Discussion}

The objective of the current study was to examine the factors which can effect on consumer intention to select healthy packaged food. There are numerous scholars who have employed theory of planned behavior for the investigation of individual intention towards any object. Therefore, proposed model of the current was underpinned with Ajzen's theory of planned behavior. The aforementioned studies reported in their empirical results that consumer's inclination towards packaged food is increasing which is becoming the cause of chronic diseases as well as obesity (Mora-Plazas, Gómez, Miles, Parra, \& Taillie, 2019). Therefore, scholars and practitioners suggested to investigate the factors which can make consumer attitude to read food label information at point of purchase for informed food choices. In continuation with researchers of the current study employed front of pack food label formats to examine their effect on consumer's attitude for reading food label. Moreover, it was also investigated that how other's influential people's opinions impact consumer's intention for healthy packaged food selection. Similarly, consumer internal strength also makes difference while taking packaged food item in their shopping cart. In addition to researchers of the current study examined the five personality traits as moderator between attitude and intention. The objective of this moderation was that past studies unfolded the fact that in three constructs of theory of planned behavior the highest explanatory power to explain intention is attitude. Therefore, the current study investigated that whether the moderation of personality can enhance or reduce the attitude and intention effect or not.

The proposed model was comprised of traffic lights label efficacy, health statement efficacy, user friendly label efficacy as behavioral beliefs for motivating consumer to make their attitude to read food label at point of purchase. Moreover, attitude to read food label was taken as mediator between behavioral beliefs and intention. On the other hand the direct effect of subjective norm and self-efficacy examined on intention. Furthermore, big five personality traits were taken as moderator between attitude and intention. The researchers of the current study investigated the each personality traits effect individual. The objective of this individual effect was to examine which traits enhance or reduce the relationship explanatory power between attitude and intention. The outcome of the analysis revealed that although in past literature traffic lights color coded label significantly effects in making consumer attitude to read food label (Olstad, Vermeer, McCargar, Prowse, \& Raine, 2015) but in current study traffic lights efficacy has insignificant effect on consumer attitude as well as insignificant impact on consumer intention. Similar result has also been observed in past studies where consumer could not understand the color coded scheme of nutritional information (Sacks et al., 2009) at food label. The cause is that participants could not understand the association of traffic lights color red, yellow and green with nutrients like calories, salt and fiber. On the other hand the positive and significant results of traffic lights labels demonstrate the consumer insight about traffic lights colors and nutritional information.

Moreover, health statement is another format of front of pack labeling. Food processing companies most often for the convenience of consumer write some short sentences related to various nutrients like 'high fiber', 'low calories', 'medium salt' at the front of the food label. Consumer can easily understand the nutrients level in food items and as per their 
body requirement select packaged food. The results of these statements are very positive and significant when examined in mediation effect. The direct effect of health statement on intention was insignificant. On the other hand when tested with the mediation of food label reading attitude the impact was positive and significant. This result unfolded the fact that uttering health statement in advertisement cannot influence consumer but when statement written on food label can have positive effect. Similar results observed in past studies (Muth et al., 2013) and aforementioned studies accounted that health statements are beneficial for educating consumer at point of purchase.

Although front of pack label provide better insights about nutrients as compare to back of pack nutrients fact panel but it was also observed in past studies that consumer demand overall food label efficacy. The crowded food label make consumer confused. In continuation with the presence of front of pack label voluntary information with traffic lights colors and health statements as well as back of pack mandatory information with nutritional fact panel disturb consumer attitude and later divert the intention from healthy packaged selection to taste oriented packaged food (Sharf et al., 2012). Therefore, most often consumer demand over all less crowded food labels. The results of current study also witnessed that the relationship of food label efficacy has positive effect on intention with the mediation of food label attitude. On the other hand the direct effect of food label efficacy was insignificant.

The current study investigated the impact of the social influential people's opinions on consumer as well as consumer own internal strength for the selection of healthy packaged food. The results of present study linked with past studies. The direct impact of subjective norm and self-efficacy was tested in current study. Subjective norm and self efficacy significantly effect on consumer intention to choose healthy packaged food items. Similar results found in aforementioned studies (Kothe \& Mullan, 2015). Self-efficacy is the individual convincing ability towards specific object which is being introduced by Bandura (1982). Past studies reported that self-efficacy for health maintenance play vital role. Consumer internal willingness for healthy diet make consumer able to select healthy food in both form fresh and packaged and strongly predict healthy life.

It is a common notion that food selection decision is taste oriented and taste motivate consumers to select food items. Consumer past experiences regarding food choices most often influence consumer present and future food selection. Nevertheless, the researchers of the current study examined personality traits effect on consumer intention to select healthy packaged food. Five personality traits employed in current study as moderator between attitude and intention. The results demonstrated that agreeableness and conscientiousness reduce the explanatory power of attitude on intention. Similar results are found in the past studies (Chapman, Fiscella, Duberstein, Coletta, \& Kawachi, 2009).

\section{Limitation}

The current study contributed in existing literature regarding finding the factors which make consumer intention to select healthy packaged food. Nevertheless due to some constraints current study has faced limitations. Although strong intention leads towards strong 
actual behavior but there are some studies which have reported that reported opinions of participants are different their actual behavior at point of purchase for packaged food items. Therefore, future researchers should examined actual behavior of consumer for packaged food selection. Similarly, the cross-sectional data most often provide the existing decisions of individuals which can be altered later with the influence of some factors. For better understanding of consumer opinions and their consistent behavior towards healthy packaged food selection future researchers should aopte longitudinal method for data collection.

Furthermore, in future consumer should identify the reasons which create hindrance for consumers to read food label at point of purchase. In continuation with the effect of food label reading vary from product to product therefore, future researchers should make list of packaged food items and then examine consumer food label reading effect on relevant food items.

\section{Conclusion}

Owing to the increasing trends of consumer to consume packaged food items the transformation of diseases observed from acute to chronic. It is necessary to educate consumer to select healthy packaged food items but as per the need of their diet. The right nutrients at the right time with right amount can prevent consumer from obesity and overweight which later become the cause of chronic diseases. The goal of the study was to identify the factors which can make consumer attitude to consult food label at point of purchase because food label is the sole method to educate consumer for right packaged food. Therefore, a model was proposed with the help of theory of planned behavior, because strong consumer intention and behavior is required for healthy packaged food items.

Food processing companies provide nutrient information at food label on back of pack labeling which is mandatory for all companies to disclose food nutrients for consumers. These back of pack label information is very technical and need special nutritional skill to understand. Therefore, scholars and practitioners suggested using front of pack label with easy to understand information for common consumer to select healthy packaged food items. The current study involved front of pack label formats like traffic light label and health statement to investigate their effect on consumer food label reading attitude. Moreover, it was also investigated that what will be the impact of over food label user friendliness on consumer label reading attitude. In addition to for healthy packaged food selection researchers of the current study examined the effect of subjective norm and selfefficacy for developing consumer intention. The personality traits were also employed as moderator. The current study adopted mixed method for detail investigation of consumer intention towards healthy packaged food selection. The aforementioned studies results witnessed the decisiveness of qualitative methods (Lioutas, 2014). Although food processing companies following the mandatory law regarding food label information nevertheless they should not only follow the law but to guide and educate consumer to select right product from available packaged food items. 


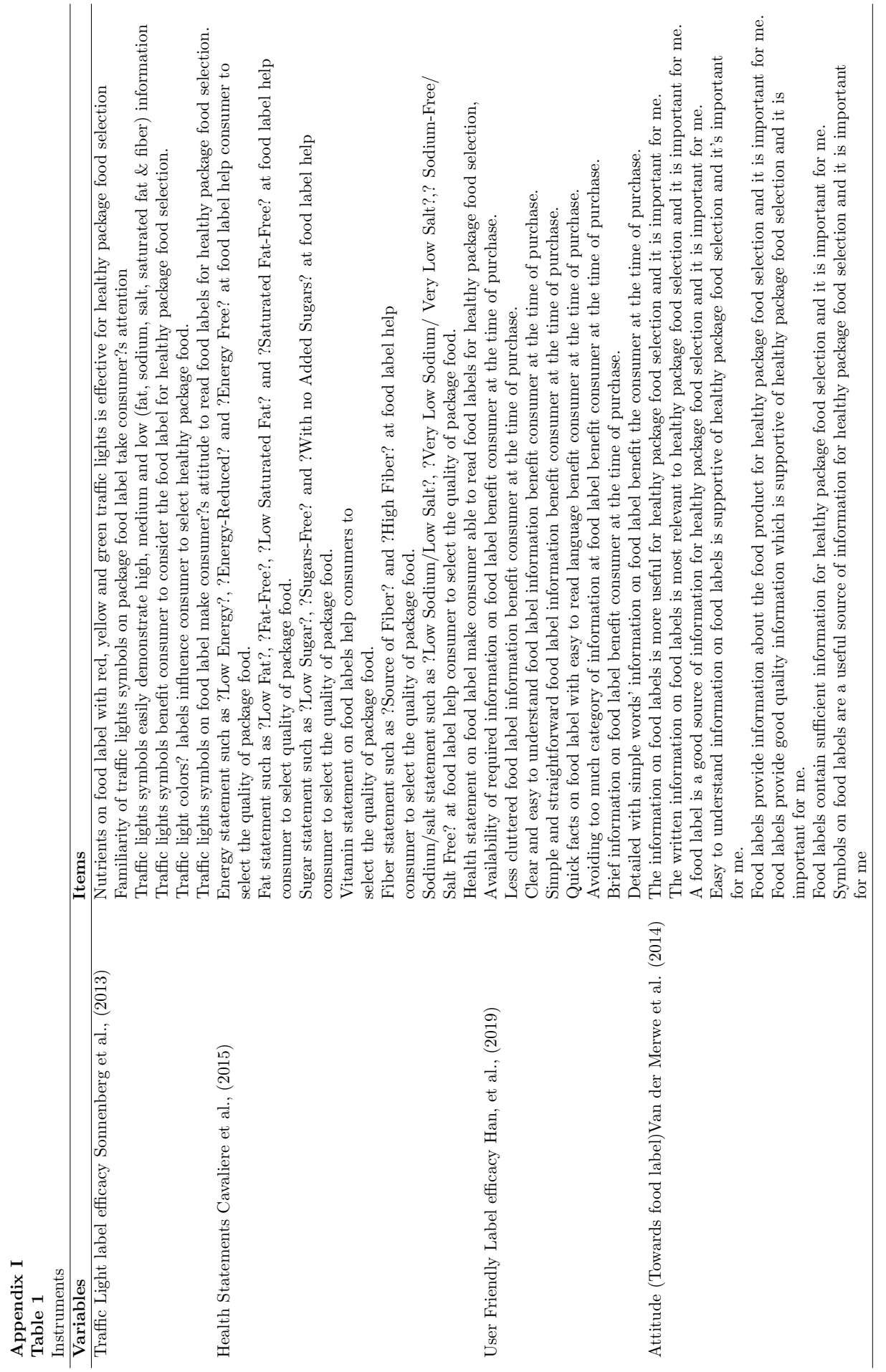




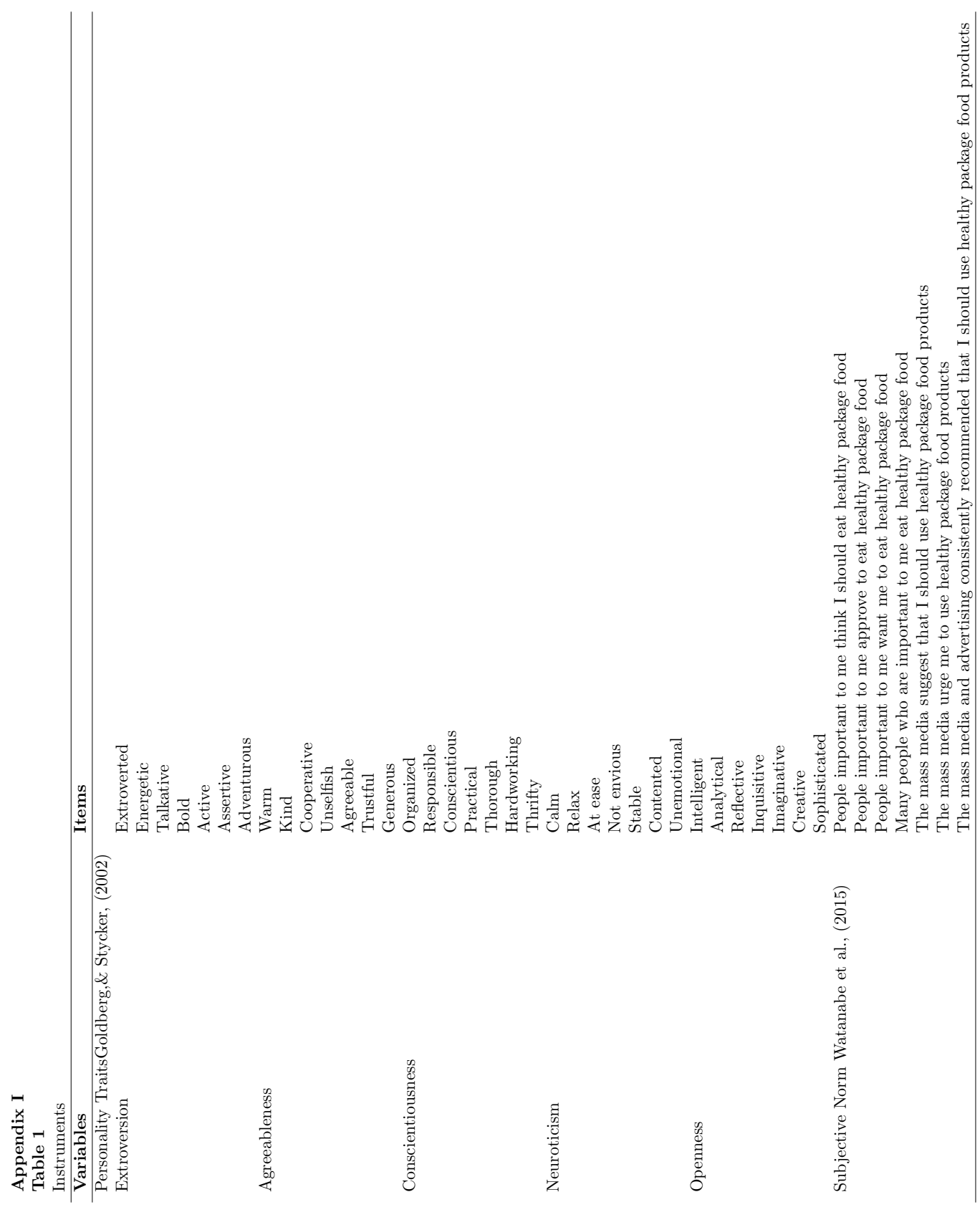




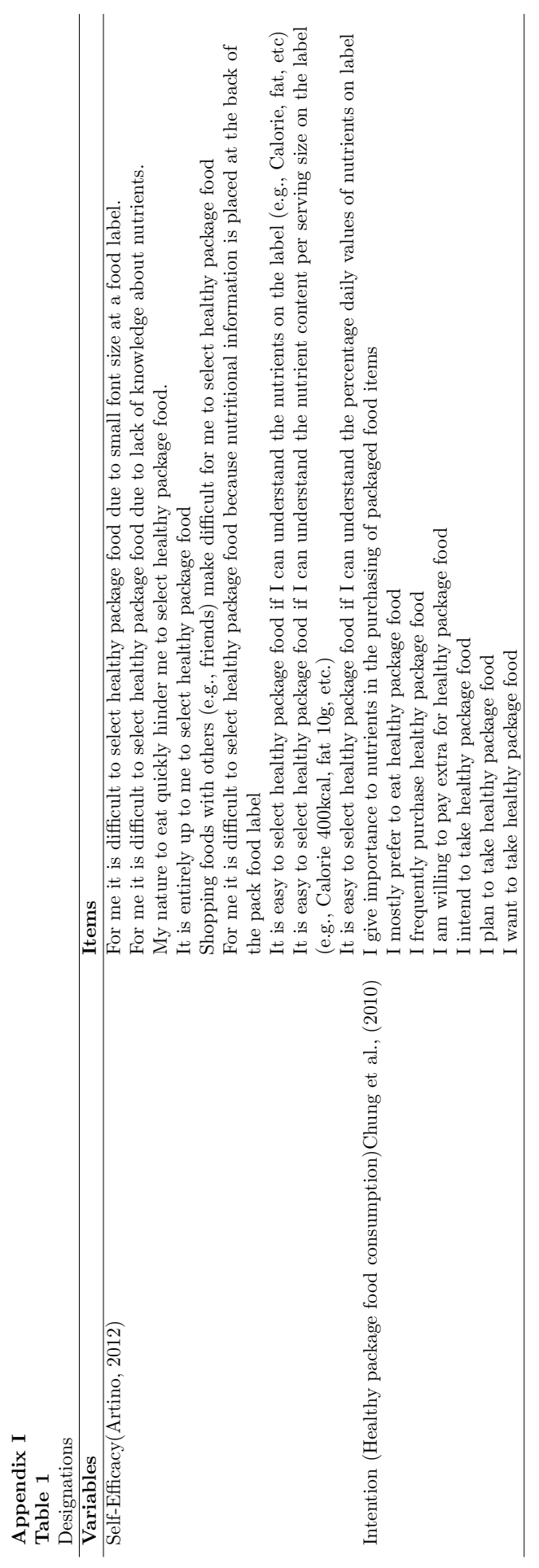




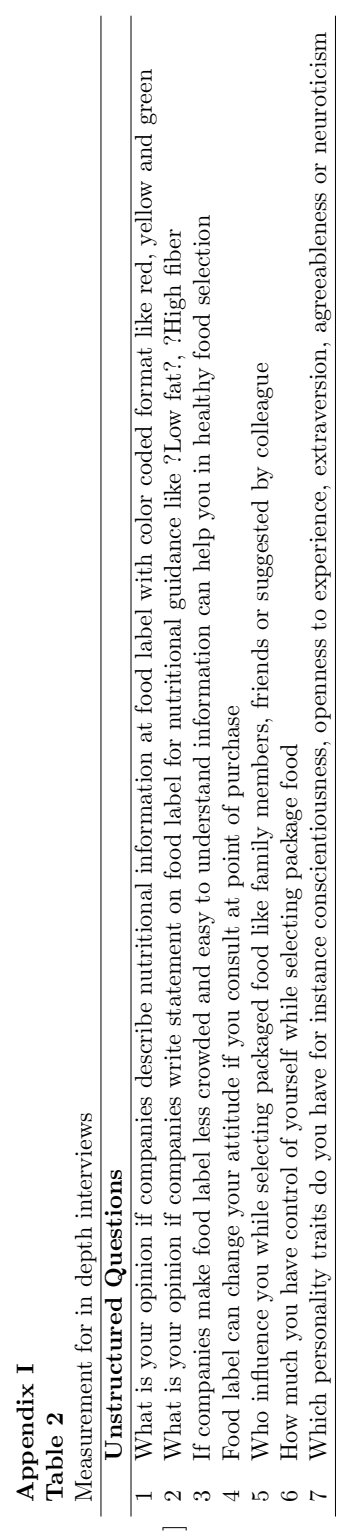




\section{References}

Ajzen, I. (1991). The theory of planned behavior. Organizational Behavior and Human Decision Processes, 50(2), 179-211.

Ajzen, I. (2020). The theory of planned behavior: Frequently asked questions. Human Behavior and Emerging Technologies, 2(4), 314-324.

Anastasiou, K., Miller, M., \& Dickinson, K. (2019). The relationship between food label use and dietary intake in adults: A systematic review. Appetite, 138, 280-291.

Asif, M., Xuhui, W., Nasiri, A., \& Ayyub, S. (2018). Determinant factors influencing organic food purchase intention and the moderating role of awareness: A comparative analysis. Food Quality and Preference, 63, 144-150.

Ayaz, A., Dedebayraktar, D., Inan-Eroglu, E., Besler, H. T., \& Buyuktuncer, Z. (2020). How does nutrition education contribute to the consumers' use and attitudes towards food labels? Nutrition \& Food Science, 51(3), 517-528.

Baker, P., Machado, P., Santos, T., Sievert, K., Backholer, K., Hadjikakou, M., ... others (2020). Ultra-processed foods and the nutrition transition: Global, regional and national trends, food systems transformations and political economy drivers. Obesity Reviews, 21(12).

Bandura, A. (1982). Self-efficacy mechanism in human agency. American Psychologist, $37(2), 122-147$.

Banovic, M., Reinders, M. J., Claret, A., Guerrero, L., \& Krystallis, A. (2019). A crosscultural perspective on impact of health and nutrition claims, country-of-origin and eco-label on consumer choice of new aquaculture products. Food Research International, 123, 36-47.

Bukhari, F., Hussain, S., Ahmed, R. R., Streimikiene, D., Soomro, R. H., \& Channar, Z. A. (2020). Motives and role of religiosity towards consumer purchase behavior in western imported food products. Sustainability, 12(1), 356. doi: 10.3390/su12010356

Cai, R., \& Leung, X. Y. (2020). Mindset matters in purchasing online food deliveries during the pandemic: The application of construal level and regulatory focus theories. International Journal of Hospitality Management, 91. doi: 10.1016/j.ijhm.2020.102677

Capacci, S., Mazzocchi, M., Shankar, B., Brambila Macias, J., Verbeke, W., Pérez-Cueto, F. J., ... others (2012). Policies to promote healthy eating in Europe: A structured review of policies and their effectiveness. Nutrition Reviews, 70(3), 188-200.

Chang, H.-P., Ma, C.-C., \& Chen, H.-S. (2020). The impacts of young consumers' health values on functional beverages purchase intentions. International Journal of Environmental Research and Public Health, 17(10). doi: 10.3390/ijerph17103479

Chapman, B. P., Fiscella, K., Duberstein, P., Coletta, M., \& Kawachi, I. (2009). Can the influence of childhood socioeconomic status on men's and women's adult body mass be explained by adult socioeconomic status or personality? Findings from a national sample. Health Psychology, 28(4), 419-427.

Chaturvedi, M. P., Kulshreshtha, K., \& Tripathi, V. (2020). The big five personality traits as predictors of organic food purchase intention: Evidence from an emerging market. PalArch's Journal of Archaeology of Egypt/Egyptology, 17(7), 10202-10218. 
Clarke, N., Pechey, E., Kosīte, D., König, L. M., Mantzari, E., Blackwell, A. K., ... Hollands, G. J. (2020). Impact of health warning labels on selection and consumption of food and alcohol products: systematic review with meta-analysis. Health Psychology Review, 1-24.

Coderoni, S., \& Perito, M. A. (2020). Sustainable consumption in the circular economy. an analysis of consumers' purchase intentions for waste-to-value food. Journal of Cleaner Production, 252. doi: 10.1016/j.jclepro.2019.119870

Conner, M. (2020). Theory of planned behavior. Handbook of sport psychology, 1-18.

Dalila, D., Latif, H., Jaafar, N., Aziz, I., \& Afthanorhan, A. (2020). The mediating effect of personal values on the relationships between attitudes, subjective norms, perceived behavioral control and intention to use. Management Science Letters, 10(1), 153162.

Díaz, L. D., Fernández-Ruiz, V., \& Cámara, M. (2020). An international regulatory review of food health-related claims in functional food products labeling. Journal of Functional Foods, 68, 103896.

Egnell, M., Talati, Z., Hercberg, S., Pettigrew, S., \& Julia, C. (2018). Objective understanding of front-of-package nutrition labels: An international comparative experimental study across 12 countries. Nutrients, 10(10). doi: 10.3390/nu10101542

Fornell, C., \& Larcker, D. F. (1981). Structural equation models with unobservable variables and measurement error: Algebra and statistics. Sage Publications Sage CA: Los Angeles, CA.

Goldberg, L. R. (1992). The development of markers for the big-five factor structure. Psychological Assessment, 4(1), 26.

Hagmann, D., \& Siegrist, M. (2020). Nutri-score, multiple traffic light and incomplete nutrition labelling on food packages: Effects on consumers' accuracy in identifying healthier snack options. Food Quality and Preference, 83.

Hair, J., Anderson, R., Babin, B., \& Black, W. (2010). Multivariate data analysis: A global perspective (vol. 7): Pearson upper saddle river. NJ.

Jackey, B. A., Cotugna, N., \& Orsega-Smith, E. (2017). Food label knowledge, usage and attitudes of older adults. Journal of Nutrition in Gerontology and Geriatrics, 36(1), $31-47$.

Joo, J. H., Lee, D. W., Choi, D.-W., \& Park, E.-C. (2020). Association between food label unawareness and loss of renal function in diabetes: A cross-sectional study in south korea. International Journal of Environmental Research and Public Health, 17(6), 1945.

Julia, C., Kesse-Guyot, E., Ducrot, P., Péneau, S., Touvier, M., Méjean, C., \& Hercberg, S. (2015). Performance of a five category front-of-pack labelling system-the 5-colour nutrition label-to differentiate nutritional quality of breakfast cereals in France. $B M C$ Public Health, 15(1), 1-9.

Jun, J., \& Arendt, S. W. (2016). Understanding healthy eating behaviors at casual dining restaurants using the extended theory of planned behavior. International Journal of Hospitality Management, 53, 106-115.

Kakizaki, M., Kuriyama, S., Sato, Y., Shimazu, T., Matsuda-Ohmori, K., Nakaya, N., ... Tsuji, I. (2008). Personality and body mass index: A cross-sectional analysis from 
the miyagi cohort study. Journal of Psychosomatic Research, 64(1), 71-80.

Kaur, A., Scarborough, P., \& Rayner, M. (2017). A systematic review, and meta-analyses, of the impact of health-related claims on dietary choices. International Journal of Behavioral Nutrition and Physical Activity, 14(1), 1-17.

Keller, C., \& Siegrist, M. (2015). Does personality influence eating styles and food choices? direct and indirect effects. Appetite, 84, 128-138.

Ketelsen, M., Janssen, M., \& Hamm, U. (2020). Consumers' response to environmentallyfriendly food packaging-a systematic review. Journal of Cleaner Production, 254. doi: $10.1016 /$ j.jclepro.2020.120123

Khandpur, N., Sato, P. d. M., Mais, L. A., Martins, A. P. B., Spinillo, C. G., Garcia, M. T., ... Jaime, P. C. (2018). Are front-of-package warning labels more effective at communicating nutrition information than traffic-light labels? A randomized controlled experiment in a brazilian sample. Nutrients, 10(6), 688. doi: 10.3390/nu10060688

Kothe, E. J., \& Mullan, B. A. (2015). Interaction effects in the theory of planned behaviour: Predicting fruit and vegetable consumption in three prospective cohorts. British Journal of Health Psychology, 20(3), 549-562.

Liou, D., \& Kulik, L. (2020). Self-efficacy and psychosocial considerations of obesity risk reduction behaviors in young adult white Americans. Plos one, 15(6).

Lioutas, E. D. (2014). Food consumer information behavior: Need arousal, seeking behavior, and information use. Journal of Agricultural \&6 Food Information, 15(2), $81-108$.

Maleksaeidi, H., Ranjbar, S., Eskandari, F., Jalali, M., \& Keshavarz, M. (2018). Vegetable farmers' knowledge, attitude and drivers regarding untreated wastewater irrigation in developing countries: A case study in Iran. Journal of Cleaner Production, 202, $863-870$.

Miocevic, D., \& Zdravkovic, S. (2020). Expatriate consumers' adaptations and food brand choices: A compensatory control perspective. Journal of International Marketing, $28(4), 75-89$.

Mora-Plazas, M., Gómez, L. F., Miles, D. R., Parra, D. C., \& Taillie, L. (2019). Nutrition quality of packaged foods in Bogotá, Colombia: A comparison of two nutrient profile models. Nutrients, $11(5), 1011$.

Muth, M. K., Zhen, C., Taylor, J., Cates, S., Kosa, K., Zorn, D., \& Choiniere, C. (2013). The value to consumers of health labeling statements on breakfast foods and cereals. Journal of Food Products Marketing, 19(4), 279-298.

Nam, S.-J. (2020). Moderating effects of consumer empowerment on the relationship between involvement in eco-friendly food and eco-friendly food behaviour. International Journal of Consumer Studies, 44(4), 297-305.

Neuhofer, Z., McFadden, B. R., Rihn, A., Wei, X., Khachatryan, H., \& House, L. (2020). Can the updated nutrition facts label decrease sugar-sweetened beverage consumption? Economics $\&$ Human Biology, 37.

Neulinger, A., Bársony, F., Gjorevska, N., Lazányi, O., Pataki, G., Takács, S., \& Török, A. (2020). Engagement and subjective well-being in alternative food networks: The case of hungary. International Journal of Consumer Studies, 44(4), 306-315.

Nguyen, N., Nguyen, H. V., Nguyen, P. T., Tran, V. T., Nguyen, H. N., Nguyen, T. M. N., 
... Nguyen, T. H. (2020). Some key factors affecting consumers' intentions to purchase functional foods: A case study of functional yogurts in Vietnam. Foods, $9(1), 24$.

Nieto, C., Tolentino-Mayo, L., Monterrubio-Flores, E., Medina, C., Patiño, S. R.-G., Aguirre-Hernández, R., \& Barquera, S. (2020). Nutrition label use is related to chronic conditions among Mexicans: Data from the Mexican National Health and Nutrition Survey 2016. Journal of the Academy of Nutrition and Dietetics, 120(5), 804-814.

Nunnally, J. C. (1994). Psychometric theory. Tata McGraw-hill education.

Nystrand, B. T., \& Olsen, S. O. (2020). Consumers' attitudes and intentions toward consuming functional foods in norway. Food Quality and Preference, 80, 103827.

Olstad, D. L., Vermeer, J., McCargar, L. J., Prowse, R. J., \& Raine, K. D. (2015). Using traffic light labels to improve food selection in recreation and sport facility eating environments. Appetite, 91, 329-335.

Pfeiler, T. M., \& Egloff, B. (2020). Personality and eating habits revisited: Associations between the big five, food choices, and body mass index in a representative Australian sample. Appetite, 149, 104607.

Pomeranz, J. L., Wilde, P., Mozaffarian, D., \& Micha, R. (2019). Mandating frontof-package food labels in the US-What are the first amendment obstacles? Food Policy, 86, 101722.

Pourmoradian, S., Kermanshahi, M., Chaeipeima, M., Farazkhah, T., \& Roudsari, A. (2020). Consumers' knowledge, attitude, and practice regarding front-of-package (FOP) labels at the point of purchase.

Rizkitysha, T. L., \& Hananto, A. (2020). Do knowledge, perceived usefulness of halal label and religiosity affect attitude and intention to buy halal-labeled detergent? Journal of Islamic Marketing.

Rohman, F., Abadi, Y. B., Soelton, M., Prasetyo, N., \& Saratian, E. T. (2020). The effect of environmentally friendly paper toward purchasing intention. In 4th International Conference on Management, Economics and Business (ICMEB 2019) (Vol. 2, pp. 120-126).

Sacks, G., Rayner, M., \& Swinburn, B. (2009). Impact of front-of-pack 'traffic-light' nutrition labelling on consumer food purchases in the UK. Health Promotion International, 24(4), 344-352.

Sharf, M., Sela, R., Zentner, G., Shoob, H., Shai, I., \& Stein-Zamir, C. (2012). Figuring out food labels. young adults' understanding of nutritional information presented on food labels is inadequate. Appetite, 58(2), 531-534.

Sivrikaya, K. K., \& Pekerşen, Y. (2020). The impact of food neophobia and sensation seeking of foreign tourists on the purchase intention of traditional turkish food. International Journal of Gastronomy and Food Science, 21.

Tan, K. Y., van der Beek, E. M., Kuznesof, S. A., \& Seal, C. J. (2016). Perception and understanding of health claims on milk powder for children: A focus group study among mothers in indonesia, singapore and thailand. Appetite, 105, 747-757.

Van Herpen, E., \& Van Trijp, H. C. (2011). Front-of-pack nutrition labels. their effect on attention and choices when consumers have varying goals and time constraints. 
Appetite, 57(1), 148-160.

Vermote, M., Bonnewyn, S., Matthys, C., \& Vandevijvere, S. (2020). Nutritional content, labelling and marketing of breakfast cereals on the belgian market and their reformulation in anticipation of the implementation of the nutri-score front-of-pack labelling system. Nutrients, $12(4), 884$.

Werle, C. O., Trendel, O., \& Ardito, G. (2013). Unhealthy food is not tastier for everybody: The "healthy= tasty" french intuition. Food Quality and Preference, 28(1), 116-121.

Yasunaga, A., \& Yaguchi, K. (2014). Personality traits, self-efficacy for exercise, and exercise levels in older Japanese adults. Health Psychology Research, 27(1), 1-11. 